\title{
Medical Thoracoscopy for the Management of Exudative Pleural Effusion: A Retrospective Study
}

This article was published in the following Dove Press journal:

Risk Management and Healthcare Policy

\author{
Ling Gong ${ }^{1,2}$ \\ Guichuan Huang ${ }^{2}$ \\ Yi Huang ${ }^{2}$ \\ Daishun Liu ${ }^{2}$ \\ Xiaoping Tang ${ }^{1}$
}

'The First Clinical Medical College, Jinan University, Guangzhou 5I0632, People's Republic of China; ${ }^{2}$ Department of Respiratory Medicine, The First People's Hospital of Zunyi (The Third Affiliated Hospital of Zunyi Medical University), Zunyi 563000, People's Republic of China

Correspondence: Xiaoping Tang The First Clinical Medical College, Jinan University, 60I W. Huangpu Avenue, Guangzhou 510632, People's Republic of China

Tel +86-1350I525993

Email txpdoc@I26.com

Daishun Liu

Department of Respiratory Medicine, The First People's Hospital of Zunyi (The Third Affiliated Hospital of Zunyi Medical University), 98 Fenghuang North Road,

Zunyi 563000, People's Republic of China Email Idsdoc@I26.com
Objective: The aim of this study was to evaluate the efficacy of medical thoracoscopy in the diagnosis and treatment of exudative pleural effusion.

Methods: A total of 82 patients with exudative pleural effusion underwent medical thoracoscopy under local anesthesia and mild sedation. The clinical characteristics, pleural fluid routine and biochemical tests, pleural biopsy, and outcomes were retrospectively evaluated. Results: Among 82 patients, the color and transparency of pleural fluid and the levels of white blood cells (WBC), lactate dehydrogenase (LDH), neutrophil proportion, lymphocyte proportion, adenosine deaminase (ADA), and glucose were different among tuberculosis (TB), malignant (M), acute and chronic inflammation ( $\mathrm{ACI}$ ), and purulent $(\mathrm{P})$ cases. Furthermore, $70 \%$ of $\mathrm{M}$ cases had a low positive rate of exfoliated cells in the sputum and pleural fluid, and more than $90 \%$ of TB cases had low positive rates of anti-tuberculosis antibodies and acid-fast bacilli in the sputum and pleural fluid. Pleural biopsy showed that $11 \%$ of cases were $\mathrm{M}, 74.4 \%$ were TB, $11 \%$ were ACI, and 3.6\% were P. Medical thoracoscopy showed that $66.7 \%$ of ACI cases had pleural adhesions, $34.4 \%$ of TB cases had moderate and $34.4 \%$ of TB cases had severe pleural adhesions, $100 \%$ of $\mathrm{M}$ and TB cases had pleural surface nodules and $77.8 \%$ of ACI cases had pleural surface nodules, $49.2 \%$ of TB cases showed encapsulated pleural effusion, and $33.3 \%$ of $\mathrm{M}$ cases showed encapsulated pleural effusion.

Conclusion: Medical thoracoscopy has high feasibility and accuracy in the diagnosis and treatment of exudative pleural effusion.

Keywords: exudative pleural effusion, medical thoracoscopy, diagnosis, treatment

\section{Introduction}

Pleural effusion is a common clinical condition characterized by pathological fluid accumulation in the pleural cavity. Clinically, common causes of exudative pleural effusion are tuberculosis, malignancy, and pneumonia. The diagnosis of exudative pleural effusion is often established by indicators such as pleural fluid routine examination and biochemical examination, and pleural fluid analysis to detect acidfast bacilli and exfoliated cells, but the accuracy is unsatisfactory. If the diagnosis cannot be established, a subsequent diagnosis and treatment plan cannot be formulated. In addition, if exudative pleural effusion is encapsulated and shows pleural adhesions, it cannot be treated promptly. According to the reports, $26 \%$ of patients with exudative pleural effusion could not be accurately diagnosed despite physical examination and pleural fluid analysis. ${ }^{1}$ Therefore, accurate diagnosis of exudative pleural effusion remains a challenge. ${ }^{2}$

Pleural biopsy is considered a decisive tool for the diagnosis of exudative pleural effusion. ${ }^{3}$ Medical thoracoscopy is a minimally invasive surgery with 
a simple operation technique, low risk, short operation time, less pain, and high sensitivity. ${ }^{4}$ Medical thoracoscopy can accurately obtain parietal pleural biopsy samples, and has been used to treat lesions such as encapsulated pleural effusion, pleural adhesion, and empyema. The use of medical thoracoscopy would help the establishment of an accurate diagnosis and formulation of subsequent treatment plans. At present, the clinical efficacy of cryotherapy or a high-frequency electrosurgical technique in the treatment of encapsulated pleural effusion and adhesions during medical thoracoscopy is encouraging. The sensitivity of medical thoracoscopy for the diagnosis of malignant pleural effusions is more than $90 \%{ }^{5}$ Medical thoracoscopy can obtain adequate pleural tissue for biopsy to facilitate the diagnosis. ${ }^{6}$ Among benign pleural effusions, tuberculous pleurisy and empyema are the most common diseases that require medical thoracoscopy. ${ }^{7}$ However, few studies have explored the potential of medical thoracoscopy in the treatment of exudative pleural effusions. Therefore, the purpose of this retrospective study was to evaluate the efficacy of medical thoracoscopy in the diagnosis and treatment of exudative pleural effusions.

\section{Methods}

\section{Subjects}

This retrospective study included participants with exudative pleural effusions who underwent medical thoracoscopy under local anesthesia and mild sedation at the Third Affiliated Hospital of Zunyi Medical University from February 2016 to April 2019. The patients were diagnosed with exudative pleural effusion based on Light's criteria. ${ }^{8}$ All patients with transudative pleural effusion, human immunodeficiency virus (HIV) infection, and contraindications to medical thoracoscopy were excluded. All participants or a parent or legal guardian for patients under the age of 18 years provided informed consent, and this study was approved by the Ethics Committee of the Third Affiliated Hospital of Zunyi Medical University and conducted in accordance with the Declaration of Helsinki.

\section{Medical Thoracoscopy Surgery}

Before surgery, blood pressure was monitored, and blood routine tests, blood ion tests, coagulation function tests, electrocardiogram, and blood gas analysis were performed. One day before medical thoracoscopy, B-scan ultrasound examination was performed, and thoracic cavity drainage was completed. If the amount of pleural effusion was small, 300-500 $\mathrm{mL}$ of filtered air was injected into the chest through a pleural drainage catheter to create an artificial pneumothorax. Ten minutes before surgery, the patients underwent intravenous injection of $2-3 \mathrm{mg}$ midazolam combined with 10-20 $\mu \mathrm{g}$ fentanyl citrate, an analgesic and sedative (sedation score of 2-3 points). The patients were placed in a supine position with the affected side facing upward. The entry point was at the level of the 5th-6th intercostal space in the mid-axillary line or the posterior axillary line. Local infiltration with $0.2 \%$ lidocaine $5-10 \mathrm{~mL}$ was performed to anesthetize the parietal pleura and make a surgical incision of about $1-2 \mathrm{~cm}$ in length. The subcutaneous tissue was bluntly separated from the thoracic cavity. A trocar cannula was inserted into the pleural cavity, and then the core was removed. Next, a flexible electronic thoracoscope (OLYMPUS LTF-240, Japan) was placed for the examination of intrathoracic lesions. In the case of encapsulated pleural effusion and adhesion, a high-frequency electrosurgical probe $(30-40 \mathrm{~W})$ was used to cut the adhesion band and biopsy forceps were used to remove the adhesion band and necrotic tissue. If nodules were found on the pleura, multiple biopsies were performed. Biopsy specimens were sent for pathological examination, and the pleural fluid was sent for routine tests for biochemical markers, ferritin, tumor markers, exfoliated cells, and acidfast bacilli. After medical thoracoscopy, the guide cannula was removed and the fluid and gas were removed from the pleural cavity. A drainage tube was inserted into the pleural cavity before the wound was closed.

\section{Data Collection}

The medical records of patients were retrospectively reviewed, and the following data were recorded: gender, age, smoking, finger pulse oxygen saturation, body temperature, clinical manifestations (including cough, expectoration, chest tightness, chest pain, night sweats, fatigue, lack of appetite, hemoptysis, shortness of breath, and weight loss), routine pleural fluid tests, pleural fluid biochemical tests, pleural fluid and sputum tests to detect exfoliated cells, serum tumor markers CA125 II, CA19-9, CA153, AFP, and CEA, pleural fluid ferritin level, pleural fluid tumor markers CA125 II, CA19-9, AFP, and CEA, acid-fast bacilli, serum anti-tuberculosis antibodies, T-cell spot test results for tuberculosis infection (T-TB.Spot), and pleural effusion B-scan ultrasound. According to the pathological examination of 
pleural biopsy, 82 patients were divided into malignant $(\mathrm{M})$ (9 cases), tuberculous (TB) (61 cases), acute and chronic inflammation (ACI) (9 cases), and purulent (P) (3 cases). The clinical characteristics, B-scan ultrasound results, biochemical and conventional results of pleural fluid, and thoracoscopy performance results were analyzed and compared. In addition, the indexes of TB pleural effusion and $\mathrm{M}$ pleural effusion confirmed by pathological biopsy were analyzed and compared.

\section{Statistical Analysis}

All statistical analyses were performed using the SPSS statistical software package (version 19.0; SPSS, Inc., Chicago, IL, USA). Normally distributed data were expressed as mean \pm standard deviation. Differences between groups were assessed using one-way ANOVA and chi-square test. Statistical significance was set at $P<0.05$.

\section{Results}

The clinical characteristics of 82 patients with exudative pleural effusion are summarized in Table 1. The proportions of gender, smoking, age, finger pulse oxygen, cough, sputum, chest tightness, chest pain, night sweats, fatigue, and lack of appetite were not significantly different among $\mathrm{M}$, TB, ACI, and P cases (all $P>0.05$ ), but there were significant differences in body temperature change among $\mathrm{M}, \mathrm{TB}, \mathrm{ACI}$, and $\mathrm{P}$ cases (all $P<0.05$ ). The temperature of patients with malignancy was normal $(100 \%)$. A maximum ratio of $37.0-38.0^{\circ} \mathrm{C}$ was noted in tuberculosis patients (19.67\%), and tuberculosis patients predominantly presented with low

Table I Clinical Characteristics of 82 Patients with Exudative Pleural Effusion

\begin{tabular}{|c|c|c|c|c|c|}
\hline & \multicolumn{4}{|l|}{ n (\%) } & \multirow[t]{2}{*}{$P$} \\
\hline & Malignant (N=9) & Tuberculous $(\mathrm{N}=6 \mathrm{I})$ & $\begin{array}{l}\text { Acute and Chronic } \\
\text { Inflammation }(\mathrm{N}=9)\end{array}$ & Purulent (N=3) & \\
\hline Gender & & & & & 0.328 \\
\hline Male & $6(66.67)$ & $4 \mid(67.2)$ & $4(44.4)$ & $3(100.0)$ & \\
\hline Female & $3(33.33)$ & $20(32.8)$ & $5(55.6)$ & $0(0.0)$ & \\
\hline Smoking & $5(55.6)$ & $23(37.7)$ & $4(44.4)$ & I (33.3) & 0.761 \\
\hline Age (years) & & & & & 0.061 \\
\hline$<18$ & $0(0.0)$ & $2(3.3)$ & $0(0.0)$ & $0(0.0)$ & \\
\hline $18-34$ & $0(0.0)$ & $16(26.2)$ & I (II.I) & $0(0.0)$ & \\
\hline $35-59$ & $5(55.6)$ & $30(49.2)$ & I (II.I) & $2(66.7)$ & \\
\hline$>59$ & $4(44.4)$ & $13(21.3)$ & $7(77.8)$ & I (33.3) & \\
\hline Body temperature $\left({ }^{\circ} \mathrm{C}\right)$ & & & & & 0.011 \\
\hline$<37.0$ & $9(100.0)$ & $33(54.1)$ & 7 (77.7) & $0(0.0)$ & \\
\hline $37.0-38.0$ & $0(0.0)$ & $12(19.7)$ & I (II.I) & $0(0.0)$ & \\
\hline $38.1-39.0$ & $0(0.0)$ & $14(22.9)$ & $0(0.0)$ & $2(66.7)$ & \\
\hline$>39.0$ & $0(0.0)$ & $2(3.3)$ & I (II.I) & I (33.3) & \\
\hline Finger pulse oxygen (\%) & & & & & 0.879 \\
\hline$<90$ & $0(0.00)$ & $4(6.6)$ & I (II.I) & $0(0.0)$ & \\
\hline $90-95$ & $3(33.3)$ & $26(42.6)$ & $4(44.4)$ & $2(66.7)$ & \\
\hline$>95$ & $6(66.7)$ & $31(50.8)$ & $4(44.4)$ & I (33.3) & \\
\hline Cough & $9(100.0)$ & 54 (88.5) & 8 (88.9) & $3(100.0)$ & 0.677 \\
\hline Expectoration & $8(88.9)$ & $4 \mathrm{I}(67.2)$ & $8(88.9)$ & $3(100.0)$ & 0.215 \\
\hline Chest tightness & $I(I I . I)$ & $21(34.4)$ & $3(33.3)$ & $0(0.0)$ & 0.335 \\
\hline Chest pain & $5(55.6)$ & $27(44.3)$ & $3(33.3)$ & $3(100.0)$ & 0.212 \\
\hline Night sweats & I (II.I) & 17 (27.9) & $0(0.0)$ & $0(0.0)$ & 0.155 \\
\hline Fatigue & $3(33.3)$ & $10(16.4)$ & $I(I I . I)$ & $0(0.0)$ & 0.467 \\
\hline Lack of appetite & $3(33.3)$ & II (I8.0) & $I(I I . I)$ & $0(0.0)$ & 0.504 \\
\hline Hemoptysis & $2(22.2)$ & I (I.6) & I (II.I) & $0(0.0)$ & 0.044 \\
\hline Shortness of breath & $7(77.8)$ & $49(80.3)$ & I (II.I) & $0(0.0)$ & 0.000 \\
\hline Weight loss & $3(33.3)$ & $48(78.7)$ & $2(22.2)$ & I (33.3) & 0.000 \\
\hline
\end{tabular}


fever. Maximum temperature ranges of $38.1-39.0{ }^{\circ} \mathrm{C}$ and $>39{ }^{\circ} \mathrm{C}$ were seen in $\mathrm{P}$ cases $(66.67 \%$ and $33.33 \%$, each). There were significant differences in hemoptysis, shortness of breath, and weight loss in M, TB, ACI, and P cases (all $P<0.05)$. The proportion of patients presenting with hemoptysis was the highest in $\mathrm{M}$ cases $(22.2 \%)$. The proportions of patients presenting with shortness of breath and weight loss were the highest in TB cases $(80.3 \%$ and $78.7 \%$, each) (all $P<0.05)$.

Table 2 shows the routine and biochemical results of pleural fluid in 82 patients with exudative pleural effusion. Among the patients, the pleural fluid to clot ratio was not significantly different among $\mathrm{M}, \mathrm{TB}, \mathrm{ACI}$, and $\mathrm{P}$ cases (all $P>0.05)$. The pleural fluid to color ratio was significantly different among M, TB, ACI, and P cases (all $P<0.05$ ). TB fluid showed grass yellow color (96.7\%), M fluid showed red color $(66.7 \%)$, and $\mathrm{P}$ fluid showed milky color $(66.7 \%)$. The pleural fluid to transparency ratio was significantly different among $\mathrm{M}, \mathrm{TB}, \mathrm{ACI}$, and $\mathrm{P}$ cases (all $P<0.05)$. In $11.1 \%$ of ACI cases, the aspirated fluid was clear and transparent; in $66.7 \%$ of $\mathrm{M}$ cases, the aspirated fluid was slightly turbid; in $36.1 \%$ of TB cases, the aspirated fluid was moderately turbid; and in $66.7 \%$ of $\mathrm{P}$ cases, the aspirated fluid was severely turbid.

WBC levels in the pleural fluid were higher in $\mathrm{P}$ cases than in $\mathrm{M}, \mathrm{TB}$, and $\mathrm{ACI}$ cases, and the difference was statistically significant (all $P<0.05$, Figure 1). The proportion of neutrophils in the pleural fluid was higher in M, ACI, and $P$ cases than in TB cases, and was higher in $P$ cases than in $\mathrm{M}$ and ACI cases, and the difference was statistically significant (all $P<0.05$, Figure 2). The proportion of lymphocytes in the pleural fluid was the highest in TB cases, higher in ACI cases, lower in M cases, and the lowest in $\mathrm{P}$ cases, and the difference was statistically significant (all $P<0.05$, Figure 3). The comparison of total protein levels, ADA levels, LDH levels, and glucose levels in the pleural fluid of different cases are shown in Figures 4-7, respectively, and the differences were statistically significant (all $P<0.05)$.

Table 3 shows the results of B-scan ultrasound examination in the 82 patients with exudative pleural effusion. The position and thickness of the pleural fluid layer were not significantly different among $\mathrm{M}, \mathrm{TB}, \mathrm{ACI}$, and $\mathrm{P}$ cases (all $P>0.05)$.

Table 4 shows tumor biomarkers in 9 patients with malignancy. The positive rate of exfoliated cells in the pleural fluid was low in $70 \%$ of patients with malignancy. The serum and pleural fluid CA125 II levels increased in more than $70 \%$ of patients with malignancy. CA19-9, AFP, and CA153 levels showed no significant changes in $80 \%$ of patients with malignancy. The serum and pleural fluid CEA levels increased, and pleural fluid ferritin levels increased in $80 \%$ of patients.

Table 5 shows TB biomarkers in 61 patients with tuberculosis. More than $90 \%$ of patients with tuberculosis had a low positive rate of acid-fast bacilli in the sputum and pleural fluid, and a low positive rate of serum antituberculosis antibodies. Although the positive rate of T-SPOT was high, there were false-negative cases.

Table 6 shows the results of medical thoracoscopic examination in the 82 patients with exudative pleural effusion. Pleural adhesion was significantly different among M, TB, ACI, and $\mathrm{P}$ cases (all $P<0.05$ ). The pleural

Table 2 Characteristics of Pleural Fluid in 82 Patients with Exudative Pleural Effusion

\begin{tabular}{|c|c|c|c|c|c|}
\hline & \multicolumn{4}{|l|}{ n (\%) } & \multirow[t]{2}{*}{$\boldsymbol{P}$} \\
\hline & Malignant ( $N=9)$ & Tuberculous $(\mathbf{N}=6 \mathrm{I})$ & $\begin{array}{l}\text { Acute and Chronic } \\
\text { Inflammation }(\mathrm{N}=9)\end{array}$ & Purulent $(\mathrm{N}=3)$ & \\
\hline Color & & & & & 0.000 \\
\hline Grass yellow & I (II.I) & 59 (96.7) & $6(66.7)$ & $0(0.0)$ & \\
\hline Yellow & $2(22.2)$ & $2(3.3)$ & $2(22.2)$ & I (33.3) & \\
\hline Red & $6(66.7)$ & $0(0.0)$ & I (II.I) & $0(0.0)$ & \\
\hline Milky & $0(0.0)$ & $0(0.0)$ & $0(0.0)$ & $2(66.7)$ & \\
\hline Clots & $5(55.6)$ & $22(36.1)$ & I (II.I) & $2(66.7)$ & 0.165 \\
\hline Transparency & & & & & 0.000 \\
\hline Clear and Transparent & $0(0.0)$ & $0(0.0)$ & I (II.I) & $0(0.0)$ & \\
\hline Slightly turbid & $6(66.7)$ & 39 (63.9) & $5(55.6)$ & $0(0.0)$ & \\
\hline Moderately turbid & $2(22.2)$ & $22(36.1)$ & $3(33.3)$ & I (33.3) & \\
\hline Severely turbid & I (II.I) & $0(0.0)$ & $0(0.0)$ & $2(66.7)$ & \\
\hline
\end{tabular}




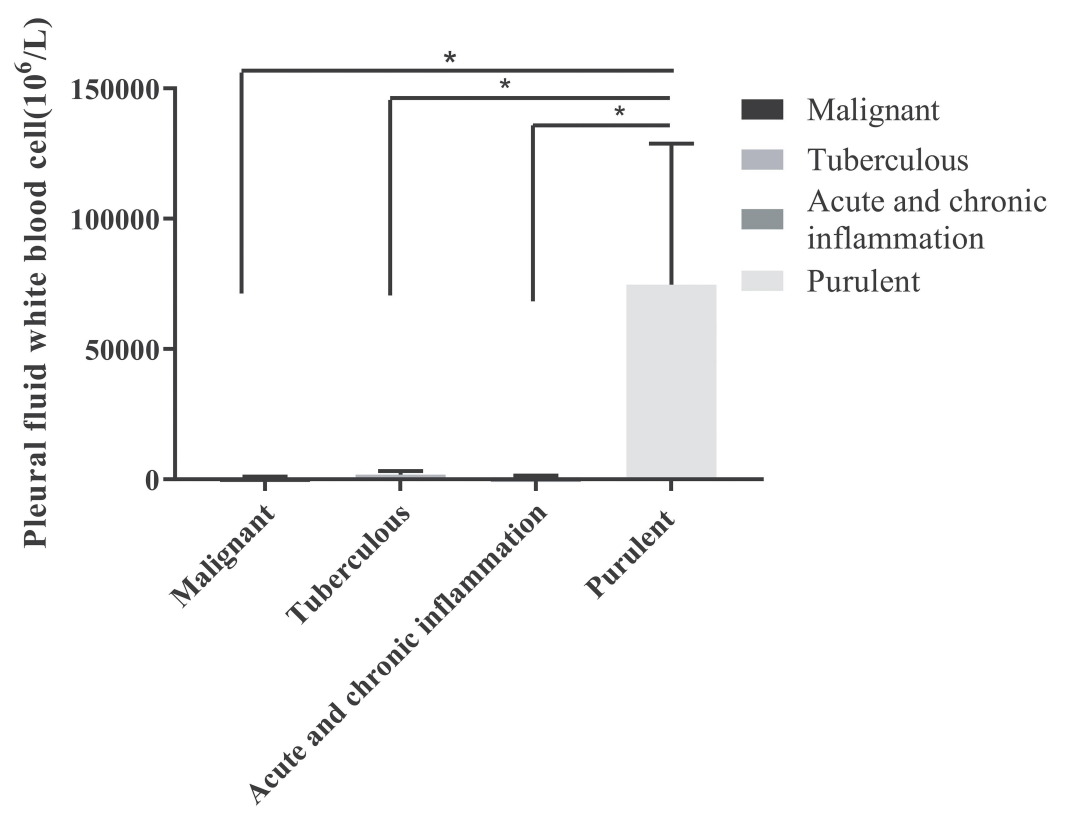

Figure I Comparison of white blood cell levels in the pleural fluid of $\mathrm{M}, \mathrm{TB}, \mathrm{ACl}$, and $\mathrm{P}$ cases. $* P<0.05$.

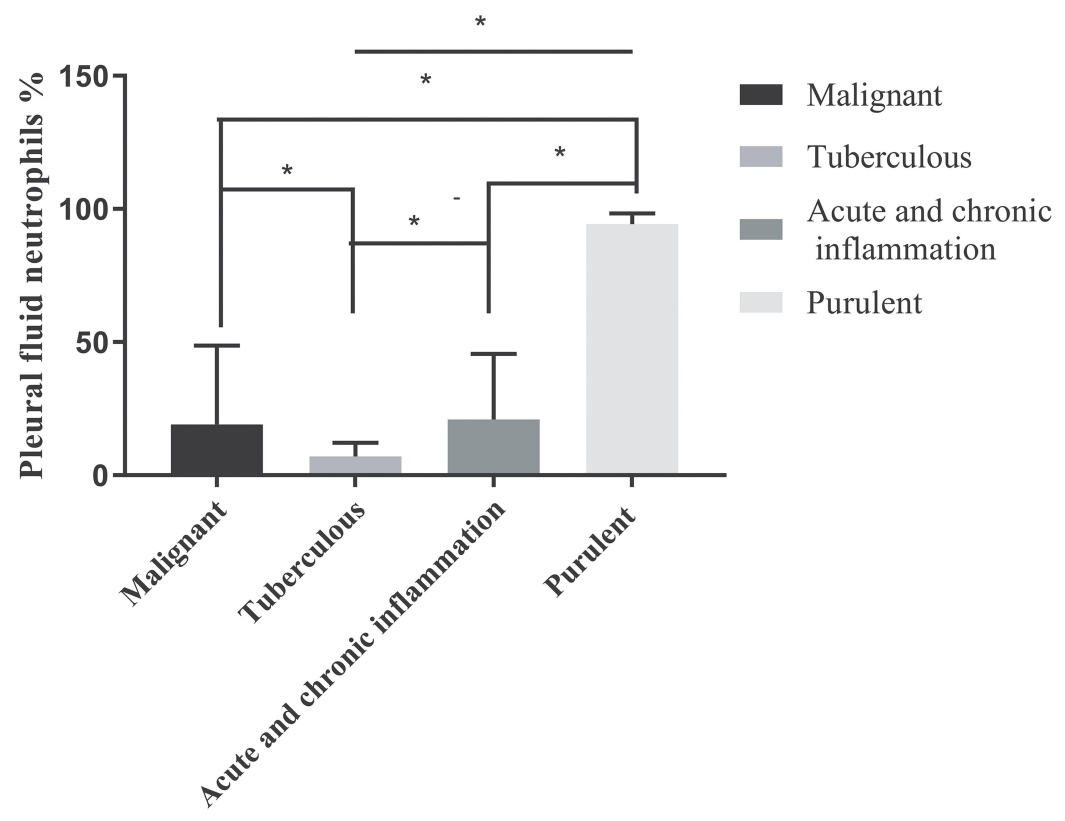

Figure 2 Comparison of the proportion of neutrophils in the pleural fluid of $\mathrm{M}, \mathrm{TB}, \mathrm{ACl}$, and $\mathrm{P}$ cases. ${ }^{*}<<0.05$.

adhesion rate was the highest in ACI cases (66.7\%), and TB cases showed a maximum rate for moderate and severe adhesions $(34.4 \%$ each, $P<0.05)$. The nodules on the pleural surface were significantly different among $\mathrm{M}$, TB, ACI, and P cases. All M and TB cases had nodules on the pleural surface $(100.0 \%)$, ACI cases also had a high rate of nodules on the pleural surface $(77.8 \%)$, and $\mathrm{P}$ cases did not have any pleural surface nodules $(0.0 \%, P<0.05)$.
The rate of encapsulated pleural effusion was significantly different among $\mathrm{M}, \mathrm{TB}, \mathrm{ACI}$, and $\mathrm{P}$ cases. The rate of encapsulated pleural effusion was the highest in TB cases (49.2\%), M cases also showed encapsulated pleural effusion (33.3\%), and ACI and P cases did not show encapsulated pleural effusion $(0.0 \%, P<0.05)$. The percentage of adhesive band release surgery was not significantly different among $\mathrm{M}, \mathrm{TB}, \mathrm{ACI}$, and $\mathrm{P}$ cases (all $P>0.05$ ). 


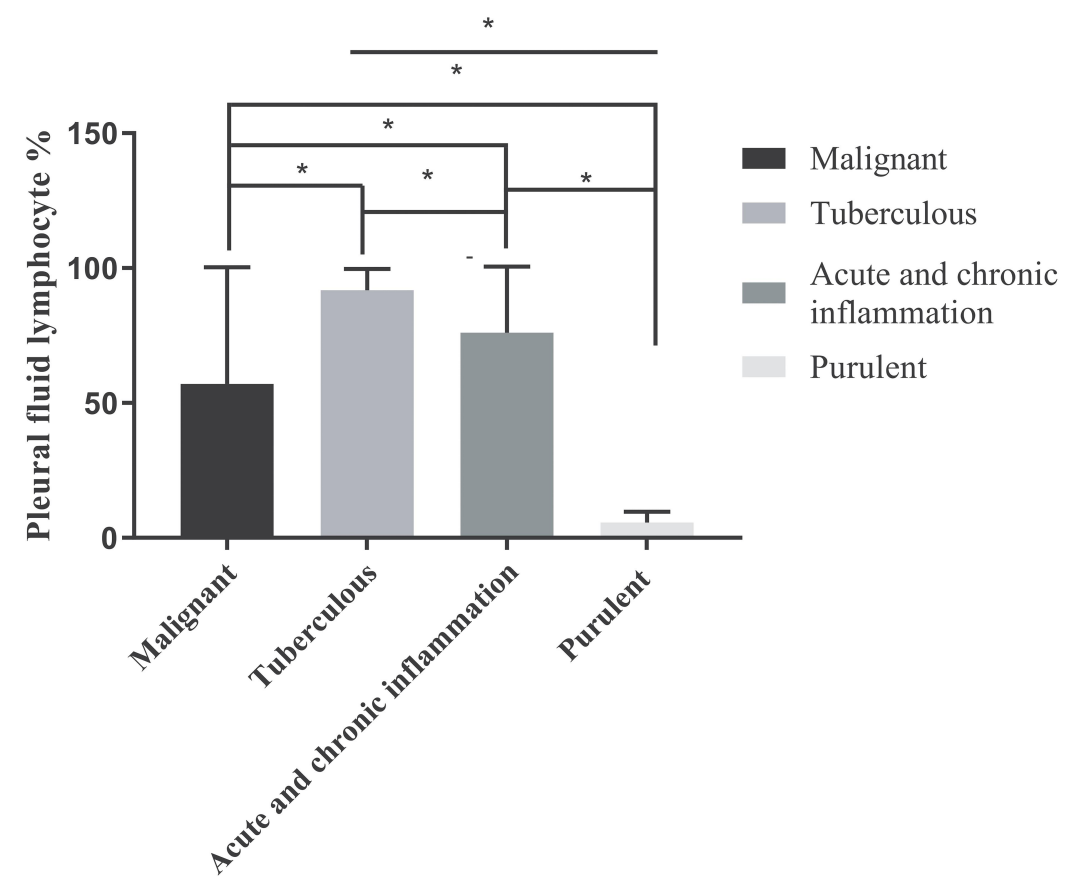

Figure 3 Comparison of the proportion of lymphocytes in the pleural fluid of $M, T B, A C l$, and $P$ cases. $* P<0.05$.

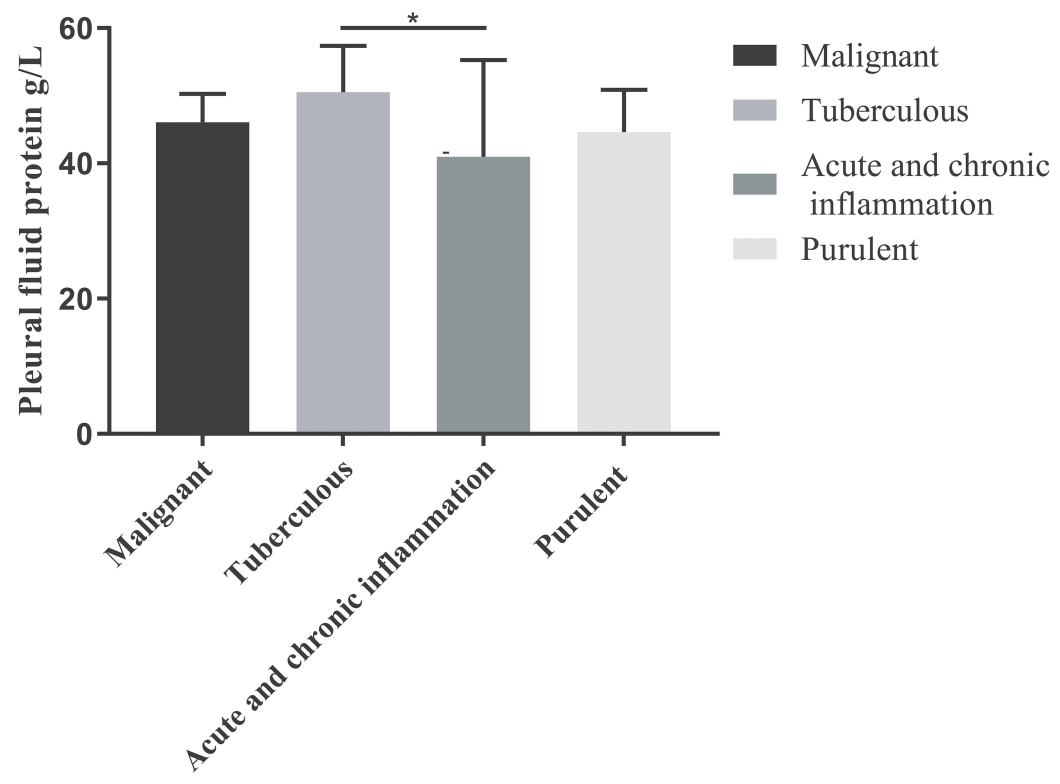

Figure 4 Comparison of total protein levels in the pleural fluid of $\mathrm{M}, \mathrm{TB}, \mathrm{ACl}$, and $\mathrm{P}$ cases. $* \mathrm{P}<0.05$.

Table 7 shows the results of pleural pathological biopsy in the 82 patients with exudative pleural effusion. Among these 82 patients, 9 cases were malignant (11\%), including 7 cases of lung adenocarcinomas (77.8\%), 1 case of lung adenosquamous carcinoma (11.1\%), and 1 case of metastases (11.1\%); 61 cases were tuberculous $(74.4 \%)$; 9 cases showed acute and chronic inflammation (11\%); and
3 cases were purulent (3.6\%). The most common cause of exudative pleural effusion was tuberculous infection, followed by malignancy, and primary malignant lung tumors accounted for $88.9 \%$ of all cases.

For side effects of medical thoracoscopy, only five cases $(6.09 \%)$ had pain, three cases $(3.65 \%)$ had subcutaneous emphysema, and one case (1.21\%) had bleeding. 


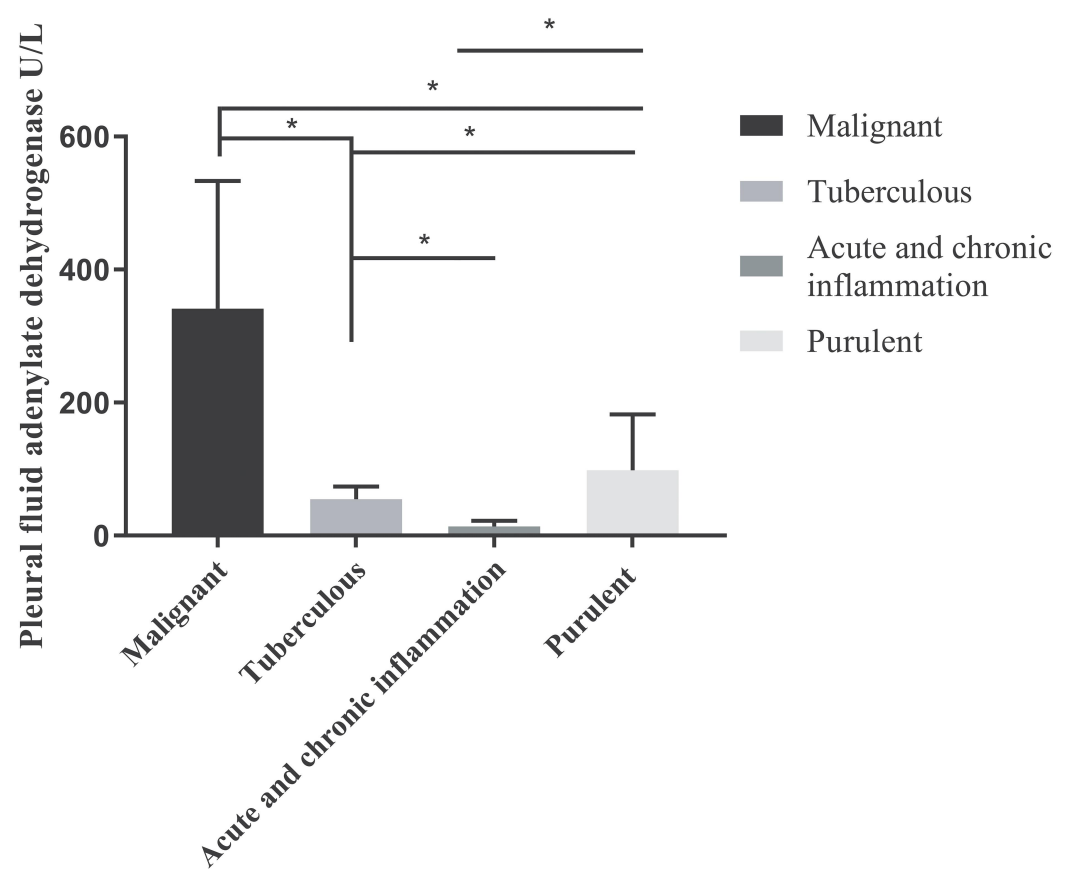

Figure 5 Comparison of adenylate dehydrogenase (ADA) levels in the pleural fluid of $M, T B, A C l$, and $P$ cases. $* P<0.05$.

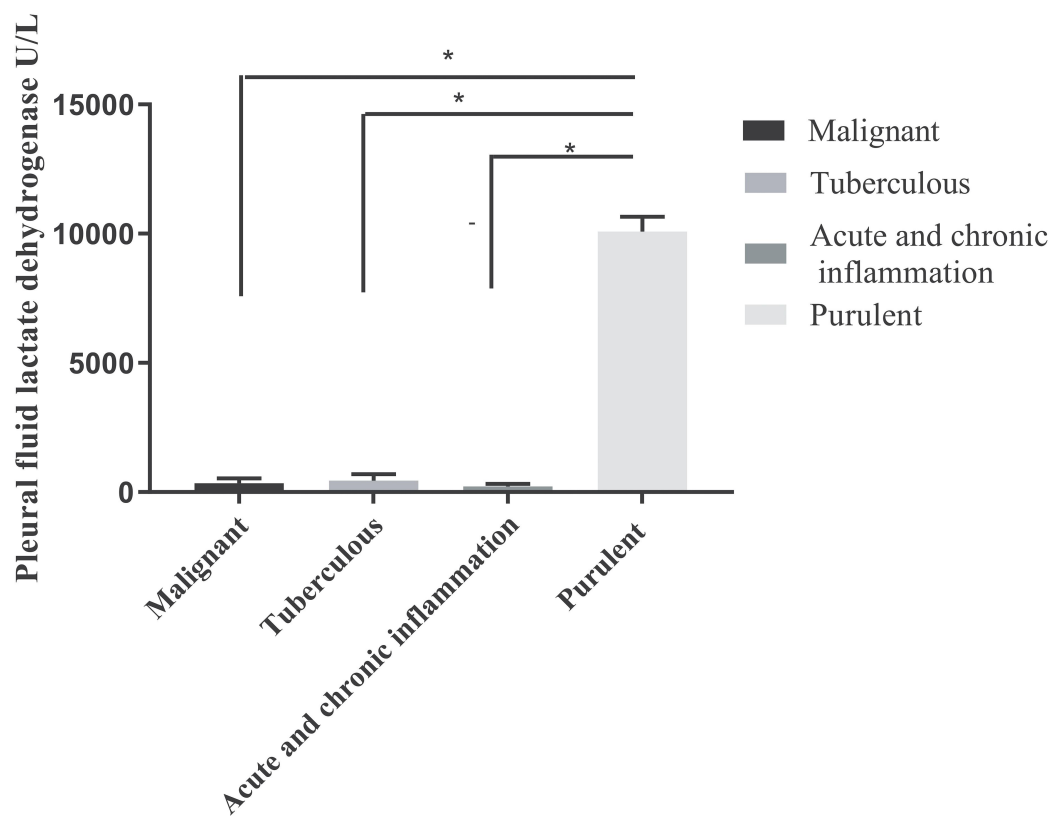

Figure 6 Comparison of lactate dehydrogenase (LDH) levels in the pleural fluid of $M, T B, A C l$, and $P$ cases. $* P<0.05$.

\section{Discussion}

Pleural infection associated with exudative pleural effusion has high morbidity and mortality, and some of these effusions eventually develop into complex effusion. ${ }^{9,10}$ The common complication of advanced malignant tumors is the development of malignant pleural effusion, which often indicates a poor prognosis. When it is difficult to establish an accurate diagnosis, pleural biopsy is required. ${ }^{11}$ In areas with high incidence of tuberculosis, due to lack of response to the tuberculin test and negative tuberculosis culture, $84.5 \%$ of tuberculous exudative pleural effusions were misdiagnosed. ${ }^{12}$ Therefore, there is an urgent need to identify the cause of exudative pleural effusion. 


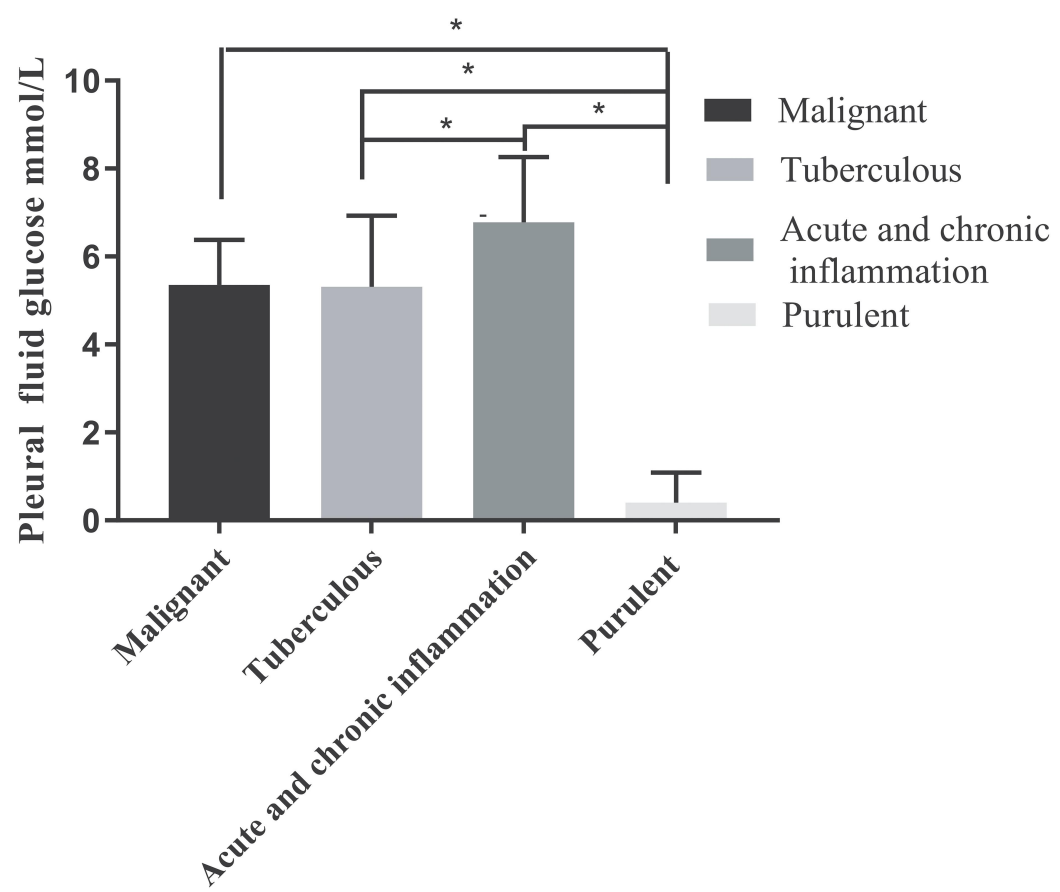

Figure 7 Comparison of glucose levels in the pleural fluid of $\mathrm{M}, \mathrm{TB}, \mathrm{ACl}$, and $\mathrm{P}$ cases. $* P<0.05$.

This study analyzed the clinical characteristics of 82 patients with exudative pleural effusion. We found that gender, smoking, age, finger pulse oxygen saturation, cough, sputum, chest tightness, chest pain, night sweats, fatigue, and lack of appetite were not significantly different among $\mathrm{M}, \mathrm{TB}, \mathrm{ACI}$, and $\mathrm{P}$ cases. Chen et al reported that smoking history and gender had no significant effect on the diagnosis of exudative pleural effusion. ${ }^{13}$ In addition, TB cases presented with low fever (19.67\%), and $\mathrm{P}$ cases presented with moderate fever and high fever (66.67\% and $33.33 \%$, each). Hemoptysis was the most common symptom in cases of malignancy $(22.2 \%)$, and shortness of breath and weight loss were the most common symptoms in cases of tuberculosis $(80.3 \%$ and $78.7 \%$, each). Because the clinical characteristics of patients with exudative pleural effusion are not significantly different, it is difficult to determine the cause only based on clinical characteristics of pleural effusion.

Next, we analyzed pleural fluid characteristics. TB fluid showed grass yellow color (96.7\%), M fluid showed red color (66.7\%), and $\mathrm{P}$ fluid showed milky color (66.7\%). In $11.1 \%$ of ACI cases, the aspirated fluid was clear and transparent; in $66.7 \%$ of $\mathrm{M}$ cases, the aspirated fluid was slightly turbid; in $36.1 \%$ of TB cases, the

Table 3 B-Scan Ultrasound of 82 Patients with Exudative Pleural Effusion

\begin{tabular}{|c|c|c|c|c|c|}
\hline & \multicolumn{4}{|l|}{ n (\%) } & \multirow[t]{2}{*}{$P$} \\
\hline & $\begin{array}{l}\text { Malignant } \\
(\mathrm{N}=9)\end{array}$ & $\begin{array}{l}\text { Tuberculous } \\
(\mathrm{N}=6 \mathrm{I})\end{array}$ & $\begin{array}{l}\text { Acute and Chronic Inflammation } \\
(\mathrm{N}=9)\end{array}$ & $\begin{array}{l}\text { Purulent } \\
(\mathrm{N}=3)\end{array}$ & \\
\hline Pleural effusion position & & & & & 0.240 \\
\hline Right side & $8(88.9)$ & $28(45.9)$ & $4(44.4)$ & $2(66.7)$ & \\
\hline Left side & I (II.I) & $27(44.3)$ & $3(33.3)$ & I (33.3) & \\
\hline Bilateral & $0(0.0)$ & $6(9.8)$ & $2(22.2)$ & $0(0.0)$ & \\
\hline Pleural effusion thickness $(\mathrm{cm})$ & & & & & 0.425 \\
\hline $2-4.9$ & $3(33.3)$ & $14(23.0)$ & $I(I I . I)$ & $2(66.7)$ & \\
\hline $5-6.9$ & $6(66.7)$ & $42(68.9)$ & 8 (88.9) & I (33.3) & \\
\hline$>7$ & $0(0.0)$ & $5(8.2)$ & $0(0.0)$ & $0(0.0)$ & \\
\hline
\end{tabular}


Table 4 Analysis of Tumor Biomarkers in 9 Patients with Malignancy

\begin{tabular}{|l|l|}
\hline Test & $\mathbf{n}(\%)$ \\
\hline $\begin{array}{l}\text { The positive rate of exfoliated cells into the pleural fluid } \\
\text { The positive rate of exfoliated cells into the sputum }\end{array}$ & $\begin{array}{l}3 / 9(33.3) \\
0 / 0(0.0)\end{array}$ \\
\hline Serum tumor markers & \\
CAI25 II & $8 / 8(100.0)$ \\
CAI9-9 & $1 / 8(12.5)$ \\
CAI53 & $1 / 8(12.5)$ \\
AFP & $0 / 8(0.00)$ \\
CEA & $6 / 8(75.0)$ \\
Pleural fluid ferritin & $4 / 5(80.0)$ \\
\hline Pleural fluid tumor markers & \\
CAI25 II & $5 / 7(71.4)$ \\
CAI9-9 & $1 / 5(20.0)$ \\
AFP & $0 / 7(0.0)$ \\
CEA & $3 / 8(37.5)$ \\
\hline
\end{tabular}

Table 5 Tuberculous Markers in 6I Patients with Tuberculosis

\begin{tabular}{|l|l|}
\hline Test & $\mathbf{n}(\%)$ \\
\hline The positive rate of acid-fast bacilli in the sputum & 0 \\
The positive rate of acid-fast bacilli in the pleural fluid & $2 / 6 \mid(3.3)$ \\
The positive rate of serum anti-tuberculosis antibodies & $4 / 58(6.9)$ \\
The positive rate of T-cell spot test results for & $29 / 3 \mathrm{I}$ \\
tuberculosis infection (T-TB.Spot) & $(93.6)$ \\
\hline
\end{tabular}

aspirated fluid was moderately turbid; and in $66.7 \%$ of $\mathrm{P}$ cases, the aspirated fluid was severely turbid. The levels of $\mathrm{WBC}, \mathrm{LDH}$, neutrophil proportion, lymphocyte proportion, ADA, and glucose were different among TB, M, $\mathrm{ACI}$, and $\mathrm{P}$ cases. Although pleural fluid routine and biochemical results of exudative pleural effusions with different etiology are different, other auxiliary tests, such as medical thoracoscopy, are needed to establish an
Table 7 Pleural Pathological Biopsy in 82 Patients with Exudative Pleural Effusion

\begin{tabular}{|l|l|}
\hline Disease Classification & n (\%) \\
\hline Malignant & $9(I I .0)$ \\
Lung adenocarcinoma & $7(77.8)$ \\
Lung adenosquamous carcinoma & 1 (II.I) \\
Metastases & I (II.I) \\
Tuberculous & $6 I(74.4)$ \\
Acute and chronic inflammation & $9($ II.0) \\
Purulent (oagulative necrosis, pus and fiber exudation) & $3(3.6)$ \\
\hline
\end{tabular}

accurate diagnosis of the etiology. In addition, B-scan ultrasound showed that pleural fluid layer position and thickness were not significantly different among $\mathrm{M}$, TB, $\mathrm{ACI}$, and $\mathrm{P}$ cases, indicating that the cause of pleural effusion could not be determined by B-scan ultrasound.

In this study, we evaluated tumor biomarkers in patients with malignant tumors, and found that $70 \%$ of patients with malignant pleural effusion had a low positive rate of exfoliated cells. Gu et al analyzed the levels of serum and pleural fluid tumor markers, and they found that CA125, CA199, and CEA had different specificities in the diagnosis of malignant pleural effusion. ${ }^{14}$ We evaluated tuberculosis markers in tuberculosis patients, and found that more than $90 \%$ of tuberculosis patients had low acid-fast bacilli in the sputum and pleural fluid, and low serum anti-tuberculosis antibodies. Although the positive rate of T-SPOT was high $(93.6 \%)$, there were false-negative cases. Gopi et al reported that mycobacteria in pleural fluid had low sensitivity, ranging from $12 \%$ to $70 \% .{ }^{15}$ Compared to thoracoscopic pleural biopsy, ADA, TB antibody test, and T-SPOT analysis lacked adequate sensitivity or specificity for TB diagnosis. ${ }^{16-18}$

Table 6 Medical Thoracoscopy of in 82 Patients with Exudative Pleural Effusion

\begin{tabular}{|c|c|c|c|c|c|}
\hline & \multicolumn{4}{|l|}{ n (\%) } & \multirow[t]{2}{*}{$P$} \\
\hline & $\begin{array}{l}\text { Malignant } \\
(\mathrm{N}=9)\end{array}$ & $\begin{array}{l}\text { Tuberculous } \\
(\mathrm{N}=6 \mathrm{I})\end{array}$ & $\begin{array}{l}\text { Acute and Chronic Inflammation } \\
(\mathrm{N}=9)\end{array}$ & $\begin{array}{l}\text { Purulent } \\
(\mathrm{N}=3)\end{array}$ & \\
\hline The degree of pleural adhesion & & & & & 0.018 \\
\hline Non-adhesive & $4(44.4)$ & $18(29.5)$ & $6(66.7)$ & $0(0.0)$ & \\
\hline Slight adhesion & I (II.I) & I (I.6) & $2(22.2)$ & I (33.3) & \\
\hline Moderate adhesion & $3(33.3)$ & $21(34.4)$ & $0(0.0)$ & I (33.3) & \\
\hline Severe adhesion & I (II.I) & $21(34.4)$ & I (II.I) & I (33.3) & \\
\hline Nodules on the pleural surface & $9(100.0)$ & $61(100.0)$ & $7(77.8)$ & $0(0.0)$ & 0.000 \\
\hline Encapsulated pleural effusion & $3(33.3)$ & $30(49.2)$ & $0(0.0)$ & $0(0.0)$ & 0.016 \\
\hline Adhesive band release surgery & $5(55.6)$ & $43(70.5)$ & $3(33.3)$ & $3(100.0)$ & 0.079 \\
\hline
\end{tabular}


Medical thoracoscopy showed that $66.7 \%$ of ACI cases had pleural adhesions, and TB cases had moderate and severe pleural adhesions. All M and TB cases had pleural surface nodules, and $77.8 \%$ of ACI cases had pleural surface nodules. Furthermore, $49.2 \%$ of TB pleural effusions were encapsulated, $33.3 \%$ of $\mathrm{M}$ pleural effusions were encapsulated, and ACI and P cases did not show encapsulated pleural effusion. Pleural pathological biopsy showed that the most common cause of exudative pleural effusion was tuberculosis, followed by malignancy. Christopher et al reported that $47 \%$ of patients with pleural effusion had a diagnosis of tuberculosis, $42 \%$ of patients with pleural effusion had a diagnosis of malignancy, and $11 \%$ of patients with pleural effusion had a diagnosis of other diseases. ${ }^{19}$ Similarly, Thomas et al reported that $84.5 \%$ of patients with exudative pleural effusion were diagnosed with tuberculosis and only $5.2 \%$ of cases were malignant. ${ }^{12}$ Chen et al reported that the most common type of malignancy was lung cancer, which accounted for $86.5 \%$ of patients with pleural metastases. ${ }^{13}$

Based on the above analysis of patients with pleural effusion, we conclude that it is difficult to accurately understand the cause of exudative pleural effusion. The pathological biopsy of pleural tissue obtained during medical thoracoscopy helps reveal the cause of exudative pleural effusion. The use of medical thoracoscopy for adhesive band removal treatment and separation of pleural effusion can promote the unblocking of capillaries and lymph vessels on the pleural surface, increase the pleural fluid reabsorption capacity, reduce the development of pleural effusion, and reduce pleural separation and adhesion, and ameliorate clinical symptoms. ${ }^{20}$ In addition, medical thoracoscopy is a minimally invasive surgery with high safety, less pain, short operation time, and high sensitivity. In this study, as side effects only five cases (6.09\%) had pain, three cases $(3.65 \%)$ had subcutaneous emphysema, and one case (1.21\%) had bleeding, consistent with a previous report. ${ }^{4}$

This study has some limitations. First, the number of cases is small, and the sample size needs to be increased. Second, this study is a single-center study, and a multicenter study is needed to verify the results. Third, all data were obtained from retrospective analysis.

In conclusion, medical thoracoscopy has high feasibility and accuracy in the diagnosis of exudative pleural effusion. Thoracoscopic treatment has good effects on encapsulated pleural effusion and pleural adhesion, and should be recommended in clinical management of exudative pleural effusion.

\section{Acknowledgment}

This study was supported by a grant from the Guizhou Provincial Natural Science Foundation Project ([2018] 5623), Zunyi Respiratory Medicine Talent Base Project ([2019]69), and Science and Technology Bureau Project of Zunyi City (Zunshi Keheshe [2018]165, Zunshi Kehe [2015]17, and Zunshi Kehe HZ[2020]3).

\section{Disclosure}

The authors report no conflicts of interest for this work.

\section{References}

1. Ali MS, Light RW, Maldonado F. Pleuroscopy or video-assisted thoracoscopic surgery for exudative pleural effusion: a comparative overview. J Thorac Dis. 2019;11(7):3207-3216. doi:10.21037/ jtd.2019.03.86

2. Huo Z, Yang M, Chen J, Peng L. Improved early diagnosis of difficult cases of tuberculous pleural effusion by combination of thoracoscopy with immunological tests. Int $J$ Infect Dis. 2019;81:38-42. doi:10.1016/j.ijid.2019.01.045

3. Haralsingh A, Rawlins R. The role of thoracoscopic biopsies in the diagnosis of pleural tuberculosis. Respir Med Case Rep. 2019;27:100846.

4. Duysinx B, Heinen V, Corhay JL, Vaillant F, Gomez A, Louis R. La thoracoscopie médicale en pratique pneumologique: expérience du CHU de Liège [Medical thoracoscopy in respiratory medicine: the Liège University Hospital experience]. Rev Mal Respir. 2019;36 (6):688-696. doi:10.1016/j.rmr.2019.02.007

5. DePew ZS, Wigle D, Mullon JJ, Nichols FC, Deschamps C, Maldonado F. Feasibility and safety of outpatient medical thoracoscopy at a large tertiary medical center: a collaborative medical-surgical initiative. Chest. 2014;146(2):398-405. doi:10.1378/chest.13-2113

6. Sahn SA. Pleural diseases related to metastatic malignancies. Eur Respir J. 1997;10(8):1907-1913. doi:10.1183/09031936.97.10081907

7. Anevlavis S, Varga C, Nam TH, et al. Is there any role for thoracoscopy in the diagnosis of benign pleural effusions. Clin Respir J. 2019;13(2):73-81. doi:10.1111/crj.12983

8. Light RW. Clinical practice. Pleural effusion. $N$ Engl $J$ Med. 2002;346(25):1971-1977. doi:10.1056/NEJMcp010731

9. Ferreiro L, San José ME, Valdés L. Management of parapneumonic pleural effusion in adults. Arch Bronconeumol. 2015;51(12):637-646. doi:10.1016/j.arbres.2015.01.009

10. Bedawi EO, Hassan M, Rahman NM. Recent developments in the management of pleural infection: a comprehensive review. Clin Respir J. 2018;12(8):2309-2320. doi:10.1111/crj.12941

11. Awadallah SF, Bowling MR, Sharma N, Mohan A. Malignant pleural effusion and cancer of unknown primary site: a review of literature. Ann Transl Med. 2019;7(15):353. doi:10.21037/atm.2019.06.33

12. Thomas M, Ibrahim WH, Raza T, et al. Medical thoracoscopy for exudative pleural effusion: an eight-year experience from a country with a young population. BMC Pulm Med. 2017;17(1):151. doi:10.1186/s12890-017-0499-y

13. Chen RL, Zhang YQ, Wang J, Wu H, Yang SM. Diagnostic value of medical thoracoscopy for undiagnosed pleural effusions. Exp Ther Med. 2018;16(6):4590-4594.

14. Gu Y, Zhai K, Shi HZ. Clinical value of tumor markers for determining cause of pleural effusion. Chin Med J (Engl). 2016;129 (3):253-258. 
15. Gopi A, Madhavan SM, Sharma SK, Sahn SA. Diagnosis and treatment of tuberculous pleural effusion in 2006. Chest. 2007;131 (3):880-889. doi:10.1378/chest.06-2063

16. Liang QL, Shi HZ, Wang K, Qin SM, Qin XJ. Diagnostic accuracy of adenosine deaminase in tuberculous pleurisy: a meta-analysis. Respir Med. 2008;102(5):744-754. doi:10.1016/j.rmed.2007.12.007

17. Steingart KR, Flores LL, Dendukuri N, et al. Commercial serological tests for the diagnosis of active pulmonary and extrapulmonary tuberculosis: an updated systematic review and meta-analysis. PLoS Med. 2011;8(8):e1001062. doi:10.1371/journal.pmed.1001062
18. Wang $\mathrm{H}, \mathrm{He} \mathrm{H}$. Characterization of multidrug-resistant Klebsiella pneumoniae isolated from the Chinese cobra Naja atra in a Beijing suburb. Biocell. 2018;42(2):47-54. doi:10.32604/biocell.2018.07006

19. Christopher DJ, Dinakaran S, Gupta R, James P, Isaac B, Thangakunam B. Thoracoscopic pleural biopsy improves yield of Xpert MTB/RIF for diagnosis of pleural tuberculosis. Respirology. 2018;23(7):714-717. doi:10.1111/resp.13275

20. Rahman NM, Ali NJ, Brown G, et al.; British Thoracic Society Pleural Disease Guideline Group. Local anaesthetic thoracoscopy: British Thoracic Society Pleural Disease Guideline 2010. Thorax. 2010;65 (Suppl 2):ii54-ii60. doi:10.1136/thx.2010.137018
Risk Management and Healthcare Policy

\section{Publish your work in this journal}

Risk Management and Healthcare Policy is an international, peerreviewed, open access journal focusing on all aspects of public health, policy, and preventative measures to promote good health and improve morbidity and mortality in the population. The journal welcomes submitted papers covering original research, basic science, clinical \& epidemiological studies, reviews and evaluations, guidelines, expert opinion and commentary, case reports and extended reports. The manuscript management system is completely online and includes a very quick and fair peer-review system, which is all easy to use. Visit http://www.dovepress.com/testimonials.php to read real quotes from published authors.

Submit your manuscript here: https://www.dovepress.com/risk-management-and-healthcare-policy-journal 